\title{
Sistema de condução em Y com e sem cobertura plástica: microclima, produção, qualidade do cacho e ocorrência de doenças fúngicas na videira 'Niagara Rosada'
}

\author{
Mário José Pedro Júnior (1,2*); José Luiz Hernandes ('); Glauco de Souza Rolim (1) \\ (') Instituto Agronômico de Campinas (IAC/APTA/SAA), Caixa Postal 28, 13020-902. Campinas (SP). E-mail: mpedro@iac.sp.gov.br \\ (*) Autor correspondente. \\ (2) Com Bolsa de Produtividade em Pesquisa do CNPq.
}

Recebido: 9/abr./2009; Aceito: 8/abr./2010

\begin{abstract}
Resumo
Foram avaliadas em Jundiaí (SP), durante os anos agrícolas de 2006/2007 e 2007/2008, as diferenças no microclima, na ocorrência de doenças fúngicas, na produção e na qualidade dos cachos em vinhedos de 'Niagara Rosada ' conduzidas no sistema em Y com e sem cobertura plástica. Os tratamentos fitossanitários para controle das doenças fúngicas foram: pulverizações semanais (Padrão) e sem aplicação de fungicida (Testemunha). Verificou-se que o uso da cobertura plástica no vinhedo não teve influência nos valores de temperatura máxima e mínima do ar. Os valores de produção nos tratamentos Padrão e Testemunha com cobertura plástica (3,52 a 6,99 $\mathrm{kg}_{\text {planta }}{ }^{-1}$ ) foram superiores ao tratamento Testemunha sem cobertura plástica (1,81 a 2,34 kg planta-1). As avaliações de ocorrência de antracnose, míldio, mancha-das-folhas e podridões permitiram verificar que no tratamento Testemunha com cobertura plástica, houve pouca incidência de doenças fúngicas até a época de colheita, apesar de não ter sido feita nenhuma aplicação de fungicida. O sistema de condução em Y com cobertura plástica permitiu a melhoria na qualidade dos cachos e diminuição na incidência de doenças fúngicas.
\end{abstract}

Palavras-chave: sistema de condução, antracnose, míldio, mancha-das-folhas, podridões, microclima, tratamento fitossanitário, cultivo protegido.

\section{Y shaped trellis system for 'Niagara Rosada' grapevine grown with and without plastic overhead cover: microclimate, yield, bunch quality and disease incidence}

\begin{abstract}
A field trial was carried out at Jundiaí, São Paulo State (Brazil), during the growing seasons of 2006/2007 and 2007/2008, in a 'Niagara Rosada' grapevine trained on a Y shaped trellis with and without plastic overhead cover aiming to evaluate the effects on: microclimate, disease incidence, yield and cluster quality. The spraying schedules used were: Standard (weekly sprays) and Control (no sprays). It was verified that the use of plastic overhead cover had no influence on maximum and minimum air temperature, and relative humidity. Yield values for the grapevines grown under plastic cover (3.52 to $6.99 \mathrm{~kg}$ plant $^{-1}$ ) were higher than the Control treatment at open sky condition (1.81 to $2.34 \mathrm{~kg}$ plant $^{-1}$ ). The evaluations of incidence of anthracnose, downy mildew, leaf spot and bunch rot allowed to verify that the Control treatment under plastic cover did not show disease incidence up to harvest, even though no fungicide was used. The $Y$ shaped trellis grapevines grown under plastic overhead cover improved cluster quality and decreased disease incidence.
\end{abstract}

Key words: trellis, plastic cover, anthracnose, downy mildew, leaf spot, bunch rot, microclimate. 


\section{INTRODUÇÃO}

O cultivo protegido em viticultura tem como objetivo, principalmente, evitar os efeitos danosos de granizo, ventos, chuvas e ataque de pássaros (Pires e Martins, 2003). Atualmente, tem havido um incremento da utilização de filme plástico de polietileno como material de cobertura das plantas o qual além de proteger contra adversidades meteorológicas, permite aumento de produtividade e obtenção de frutos de melhor qualidade (SCHUCK et al., 2004).

O uso de cobertura plástica provoca alterações no microclima do vinhedo (Ferreira et al., 2004; CARdoso et al., 2008; Chavarria et al., 2009); geralmente, as temperaturas máximas no interior do ambiente protegido são mais elevadas e as mínimas praticamente iguais ao ambiente externo (Ferreira et al., 2004; Chavarria et al., 2009). Entretanto, estas modificaçôes são dependentes do tipo de proteção utilizada e da regiáo de cultivo, tanto que Buriol et al. (1994) e LuLu et al. (2005) não observaram diferenças entre os valores de temperatura máxima e mínima na comparação do ambiente externo com o protegido por cobertura plástica. Em relaçáo à umidade relativa do ar têm sido relatados valores muito próximos interna e externamente à cobertura com plástico (SCHIEDECK et al., 1997; Chavarria et al., 2007; 2009).

A utilização de ambientes protegidos, fechados ou semifechados, tem se mostrado viável na viticultura, porém, a desvantagem de sua utilização reside, principalmente, no custo de instalação e manutenção (Oliveira, 1995). Recentemente, estudos desenvolvidos em Santa Catarina demonstraram que um dos sistemas de conduçáo da videira que mais se adapta à colocaçáo do plástico foi o manjedoura ou "Y" (EPAGRI, 2006), por facilitar sua utilização pelo viticultor.

Alguns estudos já foram efetuados no país, em diferentes sistemas de condução da videira, visando verificar a influência do uso de cobertura plástica em vinhedos em cultivares para vinho (Ferreira et al., 2004; Chavarria et al., 2009) e para mesa (SCHIEDECK et al.,1999; Lulu et al., 2005; ConCeiçấo e MARIN, 2009).

No caso da 'Niagara Rosada', para a regiâo de Bento Gonçalves, Conte (1996) e Shiedeck et al. (1999) avaliaram seu comportamento sob cobertura plástica e a céu aberto, tendo verificado que os cachos colhidos com melhor aparência e uniformidade. Em Santa Catarina, Schuck et al. (2004) relataram produtividade de $30 \mathrm{tha}^{-1}$ para a 'Niagara Rosada' conduzida sob cobertura plástica.

Uma das principais vantagens do uso de cobertura com plástico é a proteção contra a ocorrência de doenças fúngicas, uma vez que de acordo com Sônego e GarRIDo (2007) as regiôes produtoras da uva de mesa 'Niagara Rosada' são caracterizadas pelos altos índices pluviométricos e temperatura elevada durante seu período vegetativo. Estas condiçóes favorecem maior incidência de doenças e seu controle muitas vezes atinge $30 \%$ do custo de produção.

Vários autores verificaram que havia uma diminuiçáo significativa do uso de agroquímicos para controle de doenças fúngicas em videiras conduzidas sob cobertura plástica (Schuck et al., 2004; Chavarria et al., 2007; Detoni et al., 2007). Em comparação a videiras conduzidas a céu aberto, observaram ter havido um decréscimo na incidência da antracnose (Detoni et al., 2007) e de podridões (podridão-cinza-da-uva; podridão-da-uva madura e podridão-ácida) nas plantas sob cultivo protegido (LuLU et al., 2005; Chavarria et al., 2007)

As vantagens observadas nos vinhedos conduzidos sob cobertura plástica, na melhoria da qualidade dos cachos e, principalmente, na redução de doenças fúngicas motivaram o desenvolvimento deste trabalho para caracterizar as alteraçóes microclimáticas e avaliar o comportamento de videiras da cultivar 'Niagara Rosada' conduzidas em ' $\mathrm{Y}$ ' com e sem cobertura plástica visando oferecer ao viticultor nova alternativa de sistema de condução para a regiáo produtora de Jundiaí (SP).

\section{MATERIAL E MÉTODOS}

O experimento foi desenvolvido durante os anos agrícolas de 2006/07 e 2007/08 em vinhedo de 'Niagara Rosada',

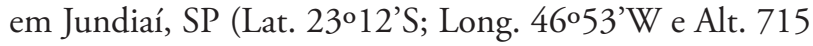
$\mathrm{m})$. As plantas foram enxertadas sobre o porta-enxertos IAC 766 'Campinas', e plantadas em espaçamento de $2 \times 1 \mathrm{~m}$. As podas curtas de inverno nos ramos do cordáo esporonado único foram realizadas em 3/8/2006 e 29/8/2007.

O sistema de condução utilizado foi uma adaptação da manjedoura em Y (Epagri, 2006), a céu aberto, como mostrado na Figura 1a, e com cobertura de plástico (filme de polietileno de baixa densidade de $150 \mu \mathrm{m}$ ) (Figura 1b).

$\mathrm{O}$ delineamento experimental utilizado foi o inteiramente casualizado com 15 plantas marcadas aleatoriamente em cada tratamento, tendo sido considerada cada planta uma repetiçáo. $\mathrm{O}$ vinhedo experimental era composto por três ruas de 30 plantas sendo $3 / 5$ da área sob cobertura plástica e $2 / 5$ a céu aberto.

Os tratamentos avaliados foram vinhedos com e sem cobertura plástica combinados com tratamentos fitossanitários: sem pulverização (Testemunha) e com pulverização semanal (Padrão). Foi aplicado o Mancozeb para controle das doenças fúngicas mais comuns na videira 'Niagara Rosada' na região: antracnose, míldio, mancha-das-folhas e podridóes.

As avaliações dos parâmetros microclimáticos foram feitas por mediçóes de temperatura do ar e umidade relativa na altura dos cachos para todos os tratamentos. As mensuraçóes foram feitas a cada minuto por sensores instalados em microabrigos e acoplados a um sistema automático de 
aquisição de dados, com amostragens a cada minuto, as quais permitiram a obtenção de médias horárias e diárias. Os sensores de temperatura do ar e umidade relativa utilizados foram do tipo ISS que compóem a estação automática Vantage Pro Plus ${ }^{\mathrm{TM}}$ da Davis Instruments.

$\mathrm{Na}$ colheita foram feitas determinaçóes em cada tratamento de produção $\left(\mathrm{kg}_{\text {planta }}{ }^{-1}\right)$, massa $(\mathrm{g})$ e número de cachos. Também foram feitas avaliações de ocorrência das doenças fúngicas: antracnose (Elsinoe ampelina (de Bary) Shear (Spphaceloma ampelinum de Bary); mildio (Plasmopara viticola (Berk. \& Curtis) Berk \& de Toni) e manchadas-folhas (Mycospharella personata Higgins (Pseudocercospora vitis (Lév.) Speg.), sinonímia de Isariopsis clavispora (Berk. \& Curtis) Sacc.), utilizando escala de notas desenvolvida por Pedro Júnior et al. (1998). As avaliaçóes de ocorrência de mancha-das-folhas foram feitas 90 dias após a colheita, quando ocorre a maior expressão da doença. A presença de podridóes (podridáo da uva madura, podridão amarga e podridáo cinzenta) e de resíduos de fungicida nos cachos foi determinada por porcentagem de ocorrência em 30 cachos colhidos aleatoriamente em cada tratamento.

Os valores médios diários dos parâmetros microclimáticos foram submetidos à análise de variância para dados pareados, enquanto os dados de produção, número e massa dos cachos e ocorrência de doenças foram avaliados por análise de variância e as médias comparadas pelo teste de Tukey a $5 \%$ de probabilidade.

\section{RESULTADOS E DISCUSSÃO}

$\mathrm{Na}$ tabela 1 são apresentados os valores médios de temperatura do ar mínima e máxima e umidade relativa medidos na altura dos cachos em plantas conduzidas com e sem cobertura plástica. Náo foram evidenciadas diferenças nos valores diários médios de temperatura máxima e mínima do ar na comparação dos ambientes protegido e sem proteção. Este fato também foi observado por Buriol et al. (1994), em túneis baixos e por Lulu et al.
(2005), em videira 'Romana' conduzida em cortina dupla sob cobertura plástica.

No caso da temperatura máxima, na regiấo de Jundiaí (SP), Ferreira et al. (2004) observaram valores maiores, em vinhedo de 'Cabernet Sauvignon' conduzido sob cobertura plástica em comparação a céu aberto. Cardoso et al. (2008) e Chavarria et al. (2009) observaram também diferenças nas temperaturas máximas em vinhedos de "Moscato Giallo" conduzidos em Y, com e sem cobertura plástica, na região de Flores da Cunha (RS). Provavelmente, as diferenças verificadas pelos autores foram em decorrência das diferentes estruturas da cobertura plástica utilizadas e localização geográfica dos vinhedos.

No caso da umidade relativa, não foi observada diferença entre os sistemas de condução. $\mathrm{O}$ vinhedo conduzido sob cobertura plástica mostrou valores de umidade relativa inferiores ao conduzido a céu aberto em cerca de $1 \%$. Buriol et al. (2000) relataram que, no interior das estufas, a umidade relativa do ar é superior em relaçáo ao ambiente externo, principalmente durante o período diurno. Por outro lado, Chavarria et al. (2007), na região de Flores da Cunha (RS), observaram que a cobertura
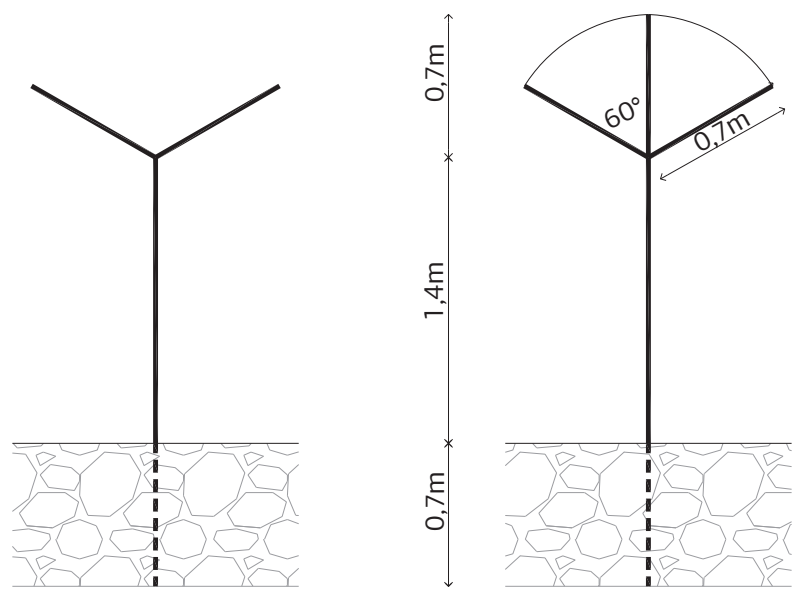

Figura 1. Sistema de condução da videira Niagara Rosada em Y a céu aberto (a) e com cobertura plástica (b). (Adaptado de EPAGRI, 2006).

Tabela 1. Temperatura do ar mínima e máxima médias, umidade relativa média e total de chuva, na altura do cacho em videiras 'Niagara Rosada' conduzidas em Y com e sem cobertura plástica, em Jundiaí (SP), durante os anos agrícolas de 2006/2007 e 2007/2008

\begin{tabular}{|c|c|c|c|c|}
\hline Variável & Com cobertura plástica & Sem cobertura plástica & DT & NS \\
\hline \multicolumn{5}{|c|}{$2006 / 2007$} \\
\hline Temperatura mínima $\left({ }^{\circ} \mathrm{C}\right)$ & 16,1 & 16,0 & 0,1 & ns \\
\hline Temperatura máxima $\left({ }^{\circ} \mathrm{C}\right)$ & 30,3 & 30,6 & $-0,3$ & ns \\
\hline Umidade relativa (\%) & 76,9 & 77,9 & $-3,0$ & * \\
\hline Chuva (mm) & 0 & 924 & & \\
\hline \multicolumn{5}{|c|}{$2007 / 2008$} \\
\hline Temperatura mínima $\left({ }^{\circ} \mathrm{C}\right)$ & 15,8 & 15,7 & 0,1 & ns \\
\hline Temperatura máxima $\left({ }^{\circ} \mathrm{C}\right)$ & 29,1 & 28,9 & 0,2 & ns \\
\hline Umidade relativa (\%) & 77,1 & 78,1 & $-4,0$ & * \\
\hline Chuva (mm) & 0 & 897 & & \\
\hline
\end{tabular}

DT: Diferença entre os tratamentos. NS: nível de significância pela análise de dados pareados. ns: não significativo. *: significativo a 5\%. 
plástica em videiras conduzidas em $\mathrm{Y}$ não influenciou a umidade relativa.

A principal diferença observada entre os sistemas de condução avaliados ocorreu, como era esperado, em relação ao total de chuva. Nos vinhedos sob a proteção da cobertura plástica não houve ocorrência direta de chuvas nas folhas e nos cachos enquanto nos vinhedos conduzidos a céu aberto foram observados valores pluviométricos entre 897 e $924 \mathrm{~mm}$ durante o ciclo da cultura. A cobertura plástica evita a ocorrência de chuvas sobre as folhas e cachos, fator determinante no desenvolvimento de doenças fúngicas.

Os resultados obtidos de produçáo, número de cachos por planta e massa dos cachos são apresentados na tabela 2. Durante o ano de 2006/2007, a produção das videiras de 'Niagara Rosada' dos diferentes tratamentos diferiram estatisticamente apenas do tratamento Testemunha sem cobertura plástica, que foi o mais prejudicado devido à maior ocorrência de doenças fúngicas. Para os tratamentos com cobertura plástica foram observadas as maiores produçóes entre 5,90 e 6,99 kg planta $^{-1}$. Esses valores são semelhantes aos observados por PEDro JúnIOR et al. (2007) para videiras 'Niagara Rosada' conduzidas em manjedoura com cordão esporonado duplo, em Jundiaí, e superiores aos relatados para a condução em espaldeira.
Ainda, no sistema em espaldeira, valores de produção relatados por diversos autores estão entre 2,5 e 4,0 kg planta ${ }^{-1}$ (Orlando et al., 2003; Terra et al., 2003).

Em relação à massa dos cachos, os maiores valores foram obtidos para os tratamentos-padrão e testemunha com cobertura plástica, variando entre 257 e 261g, respectivamente. No caso do tratamento Testemunha sem cobertura plástica foram observados valores inferiores da ordem de 147 a 168 g, em função da safra e da ocorrência de doenças fúngicas.

Durante o ano agrícola de 2007/2008 observou-se que os valores de produção, número de cachos e massa dos cachos foram inferiores aos de 2006/2007, provavelmente devido ao atraso na ocorrência das chuvas em 2007 que influiu na produção dos vinhedos, como também devido à alternância natural de safras observada na 'Niagara Rosada' na região.

Os valores de produção observados nos tratamentostestemunha e padrão com cobertura plástica e padrão sem cobertura plástica $\left(3,44\right.$ a 3,93 $\left.\mathrm{kg}_{\text {planta }}{ }^{-1}\right)$ não diferiram estatisticamente entre si, diferindo apenas do tratamentotestemunha sem cobertura plástica. A mesma tendência foi observada para massa dos cachos que variou de 147 a 233 g. Os valores mais baixos obtidos nesse ano agrícola

Tabela 2. Médias de produçâo, número de cachos e massa do cacho para a videira 'Niagara Rosada' conduzida em Y com e sem cobertura plástica, em Jundiaí (SP), durante os anos agrícolas de 2006/2007 e 2007/2008

\begin{tabular}{|c|c|c|c|c|}
\hline \multirow{2}{*}{ Variável } & \multicolumn{2}{|c|}{ Com cobertura plástica } & \multicolumn{2}{|c|}{ Sem cobertura plástica } \\
\hline & Testemunha & Padrão & Testemunha & Padrão \\
\hline & \multicolumn{4}{|c|}{$2006 / 2007$} \\
\hline Produção (kg/planta) & $6,99 \mathrm{a}$ & $5,90 \mathrm{a}$ & $2,34 \mathrm{~b}$ & $5,74 \mathrm{a}$ \\
\hline Número de cachos & $25,6 \mathrm{a}$ & $21,3 \mathrm{a}$ & 13,8 b & $22,6 \mathrm{a}$ \\
\hline \multirow[t]{2}{*}{ Massa do cacho (g) } & $261 \mathrm{a}$ & $231 \mathrm{a}$ & $168 \mathrm{~b}$ & $257 \mathrm{a}$ \\
\hline & \multicolumn{4}{|c|}{$2007 / 2008$} \\
\hline Produção (kg/planta) & $3,93 \mathrm{a}$ & $3,52 \mathrm{a}$ & $1,81 \mathrm{~b}$ & $3,44 \mathrm{a}$ \\
\hline Número de cachos & $20,3 \mathrm{a}$ & $15,3 \mathrm{a}$ & 10,3 b & $16,5 \mathrm{a}$ \\
\hline Massa do cacho (g) & $233 \mathrm{a}$ & $187 \mathrm{a}$ & $147 \mathrm{~b}$ & $193 \mathrm{a}$ \\
\hline
\end{tabular}

Médias seguidas da mesma letra na horizontal nâo diferiram entre si ao nível de $5 \%$ pelo teste de Tukey.

Tabela 3. Médias de ocorrência (\%) de antracnose, míldio, mancha-das-folhas, podridōes e presença de fungicida no cacho em videiras 'Niagara Rosada' conduzidas em Y com e sem cobertura plástica, em Jundiaí (SP), durante os anos agrícolas de 2006/2007 e 2007/2008

\begin{tabular}{|c|c|c|c|c|}
\hline \multirow{2}{*}{ Variável } & \multicolumn{2}{|c|}{ Com cobertura plástica } & \multicolumn{2}{|c|}{ Sem cobertura plástica } \\
\hline & Testemunha & Padrão & Testemunha & Padrão \\
\hline & \multicolumn{4}{|c|}{$2006 / 2007$} \\
\hline Antracnose no cacho & $3,3 \mathrm{a}$ & $3,3 \mathrm{a}$ & $23,8 b$ & $3,8 \mathrm{a}$ \\
\hline Míldio & $3,1 \mathrm{a}$ & $3,4 \mathrm{a}$ & $28,1 \mathrm{~b}$ & $3,8 \mathrm{a}$ \\
\hline Mancha-das-folhas & $37,5 \mathrm{~b}$ & $3,8 \mathrm{a}$ & $25,3 b$ & $3,8 \mathrm{a}$ \\
\hline Podridões & $3,5 \mathrm{a}$ & $3,8 \mathrm{a}$ & $60,9 \mathrm{~b}$ & $6,0 \mathrm{a}$ \\
\hline \multirow[t]{2}{*}{ Presença de fungicida } & $0,0 \mathrm{a}$ & $85,0 \mathrm{c}$ & $0,0 \mathrm{a}$ & $55,0 \mathrm{c}$ \\
\hline & \multicolumn{4}{|c|}{$2007 / 2008$} \\
\hline Antracnose no cacho & $0,0 \mathrm{a}$ & $0,0 \mathrm{a}$ & $1,5 b$ & $0,0 \mathrm{a}$ \\
\hline Míldio & $0,0 \mathrm{a}$ & $0,0 \mathrm{a}$ & $1,4 b$ & $0,0 \mathrm{a}$ \\
\hline Mancha-das-folhas & $45,8 \mathrm{~b}$ & $0,4 \mathrm{a}$ & $51,7 \mathrm{~b}$ & $1,8 \mathrm{a}$ \\
\hline Podridões & $2,8 \mathrm{a}$ & $0,6 \mathrm{a}$ & 52,7 b & $3,5 \mathrm{a}$ \\
\hline Presença de fungicida & $0,0 \mathrm{a}$ & $76,7 \mathrm{c}$ & $0,0 \mathrm{a}$ & $43,3 \mathrm{~b}$ \\
\hline
\end{tabular}

Médias seguidas da mesma letra na horizontal nâo diferiram entre si ao nível de 5\% pelo teste de Tukey. 
foram semelhantes aos obtidos por Pauletto et al. (2001) na região de Taubaté (SP).

Os valores médios de ocorrência de doenças fúngicas e presença de fungicida nos cachos estão apresentados na tabela 3. Em relação à ocorrência de antracnose e míldio, não foi observada diferença estatística entre os tratamentos com cobertura plástica (Testemunha e Padrão) e sem cobertura plástica (Padrão). Todos porém, diferiram do tratamento sem cobertura plástica (Testemunha).

Os baixos valores (0 a 3\%) de ocorrência de antracnose, míldio e podridóes nos tratamentos com cobertura plástica (Testemunha e Padrão) indicam o efeito protetivo às plantas da combinação: aplicação de fungicidas e uso de cobertura plástica. Detoni et al. (2007) também observaram em 'Cabernet Sauvignon' sob cobertura plástica, no Paraná, diminuição no nível de incidência de doenças em comparação ao cultivo a céu aberto, por ter sido verificado menor molhamento foliar sob o plástico. Ressalte-se que no tratamento com cobertura plástica (Testemunha) notaram-se baixos valores de ocorrências dessas doenças fúngicas (Tabela 3) mesmo sem realizar a aplicação de fungicida, provavelmente por impedir a ocorrência de chuvas nas folhas e nos cachos, fato também relatado por Chavarria et al. (2007).

Foi observado, para a ocorrência de podridōes, no tratamento sem cobertura plástica (Padrão), valores superiores aos tratamentos com cobertura plástica, indicando que, mesmo com uso de pulverizaçôes semanais, pode haver problema na época de colheita com essas doenças fúngicas prejudicando a qualidade dos cachos.

Em relaçáo à ocorrência de mancha-das-folhas (amostragem feita cerca de 90 dias após a colheita), o tratamento com cobertura plástica (Testemunha) não diferiu estatisticamente do tratamento sem cobertura plástica (Testemunha) indicando que apenas a proteção da cobertura plástica sem a aplicação de fungicidas não é suficiente para evitar seu aparecimento. Ou seja, para doenças do cacho, apenas o uso de cobertura plástica foi efetivo no controle das doenças fúngicas, enquanto para a manchadas-folhas é necessário o uso de fungicidas para evitar a queda prematura das folhas.

Verificou-se que o tratamento com cobertura plástica (Padrão) proporcionou elevados índices de presença de fungicida nas bagas, depreciando a qualidade do produto. Essa presença foi decorrente da proteção da cobertura plástica que, por evitar a ocorrência de chuvas diretamente nos cachos, impediu a lavagem natural do fungicida aumentando a duração de açáo do princípio ativo do produto possibilitando melhor controle das doenças fúngicas nas videiras. Também, Chavarria et al. (2007) observaram que o acúmulo residual de fungicidas foi maior no cultivo protegido quando comparado ao convencional. Além disso, deve ser ressaltado que nas condiçōes experimentais foi notado um atraso na maturaçáo dos cachos, ou seja, demoraram a atingir a coloração desejada em 'Niagara Rosada'.
A utilização do sistema de condução em Y com cobertura plástica apesar de possuir como principal desvantagem o custo de instalação, pode ser compensada pelo menor uso de fungicidas para controle de doenças fúngicas e possibilidade de colheita de cachos de melhor qualidade.

\section{CONCLUSÕES}

1. Os valores de temperatura do ar e umidade relativa médios na altura dos cachos não são influenciados pelo uso de cobertura plástica.

2. O uso do sistema de conduçấo em Y com cobertura plástica permite a obtenção de elevada produção (3,93 a 6,99 kg planta-1) e melhoria na qualidade do cacho.

3. A utilizaçáo de cobertura plástica aliado a aplicaçôes semanais de fungicidas leva à obtenção de cachos com presença de resíduos, o que diminui a qualidade.

4. A cobertura plástica permite a condução do vinhedo sem aplicação de fungicida até a época de colheita.

\section{REFERÊNCIAS}

BURIOL, G.A.; STRECK, N.A.; GIMENES, E.S.; SCHINEIDER, F.M. Alteraçôes microclimáticas causadas por túneis baixos de tela plástica preta cultivados com alface. Ciência Rural, v.24, p.1-6, 1994.

BURIOL, G.A.; RIGHI, E.Z.; SCHINEIDER, F.M.; STRECK, N.A.; HELDWEIN, A.B.; ESTEFANEL, V. Modificação da umidade relativa do ar pelo uso e manejo da estufa plástica. Revista Brasileira de Agrometeorologia, v.8, p.11-18, 2000.

CARDOSO, L.S.; BERGAMASCHI, H.; COMIRAN, F.; CHAVARRIA, G.; MARODIN, G.A.B.; DALMAGO, G.A.;SANTOS, H.P.; MANDELLI, F. Alteraçôes micrometeorológicas em vinhedos pelo uso de coberturas de plástico. Pesquisa Agropecuária Brasileira, v.43, p.441-447, 2008.

CHAVARRIA, G., SANTOS, H.P.; SÔNEGO, O.R.; MARODIN, G.A.B.; BERGAMASCHI, H.; CARDOSO, L.S. Incidência de doenças e necessidade de controle em cultivo protegido de videira. Revista Brasileira de Fruticultura, v.29, p.477-482, 2007.

CHAVARRIA, G.; CARDOSO, L.S.; BERGAMASCHI, H.; SANTOS, H.P.; MANDELLI, F.; MARODIN, G.A.B. MICROCLIMA de vinhedos sob cultivo protegido. Ciência Rural, v.39, p.2029-2034, 2009.

CONCEIÇÃO, M.A.F.; MARIN, F.R. Condiçôes microclimáticas em um parreiral irrigado coberto com tela plástica. Revista Brasileira de Fruticultura, v.31, p.423-431, 2009.

CONTE, A. Comportamento da videira 'Niagara Rosada' submetida à poda de verão, sob estufa plástica, em Bento Gonçalves. 1996. 71p. Dissertaçáo (Mestrado em Fitotecnia). Universidade Federal do Rio Grande do Sul, Porto Alegre. 
DETONI, A.M.; CLEMENTE, E.; FORNARI, C. Produtividade e qualidade da uva 'Cabernet Sauvignon' produzida sob cobertura de plástico em cultivo orgânico. Revista Brasileira de Fruticultura, v.29, p.530-534. 2007

EPAGRI. Sistema de sustentação da videira na forma de "Ypsilon" ou manjedoura com cobertura plástica. Governo de Santa Catarina. Empresa de Pesquisa Agropecuária e Extensão Rural de Santa Catarina S.A. 2p. 2006. (Fôlder)

FERREIRA, M.A.; PEDRO JUNIOR, M.J.; SANTOS, A.O.; HERNANDES, J.L. Modificação parcial do ambiente de cultivo da videira 'Cabernet Sauvignon' sobre diferentes porta-enxertos: efeito sobre a produção e o teor de sólidos solúveis. Bragantia, v.63, p.439-445, 2004.

LULU, J.; CASTRO, J.V.; PEDRO JUNIOR, M.J. Efeito do microclima na qualidade de uva de mesa 'Romana' (A1105) cultivada sob cobertura plástica. Revista Brasileira de Fruticultura, v.27, p.422-425, 2005.

OLIVEIRA, M.R.V. O emprego de casas de vegetação no Brasil: vantagens e desvantagens. Pesquisa Agropecuária Brasileira, v.30, p.1049-60, 1995.

ORLANDO, T.G.S.; REGINA, M.A.; SOARES, A.M.; CHALFUN, N.N.J.; SOUZA,C.M.; FREITAS, G.F.; TOYOTA, M. Caracterizaçẫo agronômica de cultivares de videira (Vitis labrusca L.) em diferentes sistemas de condução. Ciência e Agrotecnologia, p.1460-1469, 2003. (Edição Especial)

PAULETTO, D. Efeito do porta-enxerto na qualidade do cacho da videira 'Niagara Rosada'. Pesquisa Agropecuária Brasileira, v.36, p.935-939, 2001.

PEDRO JÚNIOR, M.J.; HERNANDES, J.L.; TECCHIO, M.A.; PEZZOPANE, J.R.M. Influência do sistema de condução no microclima, na produtividade e na qualidade de cachos da videira 'Niagara Rosada', em Jundiaí, SP. Revista Brasileira de Fruticultura, v.29, p.313-317, 2007.

PEDRO JÚNIOR, M.J.; RIBEIRO, I.J.A.; MARTINS, F.P. Microclima condicionado pela remoçáo de folhas e ocorrência de antracnose, míldio e mancha-das-folhas na videira 'Niagara Rosada'. Summa Phytopathologica, v.24, p.151-156, 1998

PIRES, E.J.P.; MARTINS, F.P. Técnicas de cultivo. In: POMMER, C.V. (Ed.). Uva: tecnologia de produção, pós-colheita, mercado. Porto Alegre: Cinco Continentes, 2003. p.351-403.

SCHIEDECK, G.; MIELE, A.; BARRADAS, C.I.N.; MANDELLI, F. Fenologia da videira Niágara Rosada em estufa e a céu aberto. Revista Brasileira de Agrometeorologia, v.5, p.199-206, 1997.

SCHIEDECK, G.; MIELE,A.; BARRADAS, C.I.N.; MANDELLI, F. Maturaçáo da uva Niágara Rosada cultivada em estufa de plástico e a céu aberto. Ciência Rural, v.29, p.629-633, 1999.

SCHUCK, E.; CALIARI, V.; ROSIER, J.P. Uso da plasticultura na melhoria da qualidade de frutas. In: ENCONTRO NACIONAL SOBRE FRUTICULTURA DE CLIMA TEMPERADO ENFRUTE, 7., Fraiburgo, Santa Catarina. Anais... Fraiburgo: EPAGRI, 2004. 9p.

SÔNEGO, O.R.; GARRIDO, L.R. Capacitação Técnica em Viticultura. Empresa Brasileira de Pesquisa Agropecuária EMBRAPA - Disponível em: http/www.cnpuv.embrapa.br / viticultura. Acesso em janeiro/2007.

TERRA, M.M. ; PIRES, E.J.P.; POMMER, C.V.; BOTELHO, R.V. Produtividade da cultivar de uva de mesa Niagara Rosada sobre diferentes porta-enxertos, em Monte Alegre do Sul-SP. Revista Brasileira de Fruticultura, v.25, p.549-551, 2003. 